\title{
Comparative study of oxidative stress caused by anthracene and alkyl-anthracenes in Caenorhabditis elegans
}

\author{
Ji-Yeon Roh ${ }^{1,2}$, Pil-Gon Kim ${ }^{1}$, Jung-Hwan Kwon ${ }^{1}$ \\ 'Division of Environmental Science and Ecological Engineering, Korea University, Seoul, Korea; ${ }^{2}$ Unit of Industrial Chemical \& Biocides, Knoell Korea Ltd., \\ Seoul, Korea
}

\begin{abstract}
Oxidative stress was evaluated for anthracene (Ant) and alkyl-Ants (9-methylanthracene [9-MA] and 9, 10-dimethylanthracene [9, 10DMA]) in Caenorhabditis elegans to compare changes in toxicity due to the degree of alkylation. Worms were exposed at 1) the same external exposure concentration and 2) the maximum water-soluble concentration. Formation of reactive oxygen species, superoxide dismutase activity, total glutathione concentration, and lipid peroxidation were determined under constant exposure conditions using passive dosing. The expression of oxidative stress-related genes (daf-2, sir-2.1, daf-16, sod-1, sod-2, sod-3 and cytochrome $35 \mathrm{~A} / \mathrm{C}$ family genes) was also investigated to identify and compare changes in the genetic responses of $C$. elegans exposed to Ant and alkyl-Ant. At the same external concentration, 9,10-DMA induced the greatest oxidative stress, as evidenced by all indicators, except for lipid peroxidation, followed by 9-MA and Ant. Interestingly, 9, 10-DMA led to greater oxidative stress than 9-MA and Ant when worms were exposed to the maximum water-soluble concentration, although the maximum water-soluble concentration of 9, 10DMA is the lowest. Increased oxidative stress by alkyl-Ants would be attributed to higher lipid-water partition coefficient and the $\pi$ electron density in aromatic rings by alkyl substitution, although this supposition requires further confirmation.
\end{abstract}

Keywords: Oxidative stress, Polycyclic aromatic hydrocarbons, Passive dosing, Gene expression, Caenorhabditis elegans.

\section{INTRODUCTION}

Toxic residues following accidental oil spills are one of the most important worldwide environmental concerns. Oils are comprised of many chemical species, including persistent, toxic, and carcinogenic compounds, such as polycyclic aromatic hydrocarbons (PAHs), alkylated PAHs (alkyl-PAHs), and a small fraction of non-hydrocarbons [1,2]. The majority of research on the toxicity of compounds in oils has focused on unsubstituted 16 PAHs classified as priority pollutants by the US Environmental Protection Agency [3,4]. However, alkyl-PAHs are found in higher quantities than unsubstituted PAHs in crude oils $[2,5,6]$ and field monitoring studies have reported that higher alkylPAHs concentrations were detected in oil-contaminated sites, in the sediment, soil, and surface water $[7,8]$. Because of the predominance of alkyl-PAHs in oils, whether alkyl-PAHs are as

Received: January 20, 2018 Accepted: February 26, 2018

Corresponding author: Jung-Hwan Kwon

Division of Environmental Science and Ecological Engineering, Korea University, 145 Anam-ro, Seongbuk-gu, Seoul 02841, Korea

E-mail: junghwankwon@korea.ac.kr

This article is available from: http://e-eht.org/ toxic as PAHs is an important question.

Several studies reported that alkyl-PAHs were more toxic than their non-alkylated counterparts based on organism-level responses [9-13]. Studies have suggested that the toxicity of alkyl-PAHs depends on the oxidative stress resulted from the metabolic process of cytochrome P450 (CYP) induced via the interaction of xenobiotics with the aryl hydrocarbon receptor (AHR), a mechanism similar to the toxicity pathway of PAHs [14-16]. For example, Mu et al. [14] supported that oxidative stress is an important toxicity pathway, leading to developmental toxicity by showing the increase in CYP activity and the response of the antioxidant system caused by alkyl-phenanthrenes. Fallahtafti et al. [10] proposed that the toxicity of alkyl-PAHs is not a response specific to the preferential formation of particular metabolites, such as those formed from CYP metabolism. However, studies to elucidate the toxic potential and mechanisms leading to oxidative stresses caused by alkylPAHs are lacking although oxidative stress is believed to be a strong inducer leading to toxic effects at the organism level (e.g., survival, behavior, and reproduction).

The main goal of the study was to compare the toxicity of Ant and alkyl-Ants on the oxidative stress of Caenorhabditis ele- 
gans under constant exposure using passive dosing. C. elegans was chosen because it is a representative soil invertebrate for (eco)toxicology whose genome has been completely sequenced [17-21]. To maintain the intended exposure concentration during the experimental period, a passive dosing method using polydimethylsiloxane (PDMS) was employed. Ant, 9-methylanthracene (9-MA) and 9,10-dimethylanthracene (9,10-DMA) were chosen as model chemicals to which the soil nematode $C$. elegans was exposed. As oxidative stressrelated end-points, reactive oxygen species (ROS) induction, superoxide dismutase (SOD) activity, total glutathione (GSH) concentration, and lipid peroxidation were measured at the same exposure concentration in the test medium, as well as at the maximum soluble concentrations of test chemicals. Oxidative stress-related genes (daf-2, sir-2.1, daf-16, sod-1, sod-2, and sod-3) and CYP metabolism-related genes (cyp35a1-5 and $c y p 35 c 1$ ) were also investigated to identify and compare changes in genetic responses in C. elegans exposed to Ant and alkyl-Ant.

\section{METHODS}

\section{Organisms}

The soil nematodes C. elegans were maintained on a nematode growth medium at $20^{\circ} \mathrm{C}$ and fed Escherichia coli strain OP50. Age-synchronized young adults (3.5 days old) were gathered according to a general nematode protocol $[17,18]$ and $100 \mu \mathrm{L}$ of worm condensate was used for all experiments (average tissue dry-weight: $10 \mathrm{mg}$ in $100 \mu \mathrm{L}$ ).

\section{Chemicals}

Ant was purchased from Sigma-Aldrich (> 99\%; CAS No. 120-12-7; St. Louis, MO, USA), and 9-MA (98\%; CAS No. 77902-2) and 9,10-DMA (98\%; CAS No. 781-43-1) were purchased from Tokyo Chemical Industry Co. (Tokyo, Japan). PDMS sheets were purchased from Specialty Silicone Products, Inc. (cat. SSP-M8232; Ballston Spa, NY, USA). High-performance liquid chromatography grade methanol and n-hexane were purchased from Honeywell Burdick \& Jackson (Ulsan, Korea).

\section{Experimental Procedures}

Methodological details for passive dosing

PDMS sheets were cut into rectangular sheets $(11 \mathrm{~mm} \times 109$ $\mathrm{mm} \times 1 \mathrm{~mm}$, density $1.17 \mathrm{~g} / \mathrm{mL}$ ) for loading with Ant and alkylAnt. The custom-cut PDMS sheets were washed twice with $n$ hexane and methanol for 2 hours each. Then, clean PDMS sheets were stored in ACS grade methanol until use. For toxicity tests, PDMS sheets were loaded with Ant and alkyl-Ant us-
Table 1. Molecular weights (MW), water solubility (S), log lipid-water partition coefficients $\left(K_{\text {lipw }}\right), \log$ PDMS-water partition coefficients $\left(K_{\text {PDMSW }}\right)$, and log PDMS-loading solution (LS) partition coefficients (KPDMSLS) of Ant and alkyl-Ants

\begin{tabular}{lccc}
\hline & Ant & 9-Methylanthracene & 9,10-Dimethylanthracene \\
\hline MW & 178.22 & 192.26 & 206.29 \\
S $(\mu \mathrm{g} / \mathrm{L})$ & 40 & 390 & 7.9 \\
$\log K_{\text {lipw }}$ & 5.28 & 5.52 & 5.78 \\
$\log K_{\text {PDMSW }}$ & 3.98 & 4.24 & 4.52 \\
$\log K_{\text {PDMSLS }}$ & 1.05 & 1.20 & 1.38 \\
\hline
\end{tabular}

PDMS, polydimethylsiloxane; Ant, anthracene.

ing a loading solution (methanol:water $=6: 4[\mathrm{v} / \mathrm{v}]$ ). Preliminary measurements of equilibrium partition coefficients between PDMS and the loading solution for Ant and alkyl-Ant (Table 1) were used to prepare the desired concentration in the exposure medium. After 24 hours, PDMS sheets were taken from the loading solution, air-dried for 1 hour, and placed in a 6 -well plate. The test medium ( $0.032 \mathrm{M}$ potassium chloride $[\mathrm{KCl}]$ and $0.051 \mathrm{M}$ sodium chloride $[\mathrm{NaCl}])$ and PDMS were pre-equilibrated for 24 hours at $20^{\circ} \mathrm{C}$ before introducing worms.

\section{Toxicity tests at the same external aqueous concentration (TEST I)}

To investigate toxic responses at the same external exposure concentration for the comparison of toxic potency, three chemicals were tested at 4.0 and $8.0 \mu \mathrm{g} / \mathrm{L}$, which was below the water solubility of the most hydrophobic chemical, 9,10DMA (Table 1). Young adults (3.5 days old) were placed in a 1 -mL tube and $100 \mu \mathrm{L}$ of worm condensate was transferred to the test medium (0.032 $\mathrm{M} \mathrm{KCl}$ and $0.051 \mathrm{M} \mathrm{NaCl})$, which had been pre-equilibrated for 24 hours with each test chemical. After pre-equilibrium, the worms were exposed for 6 and 12 hours without food.

\section{Toxicity tests at the water solubility limit of test chemicals (TEST II)}

Because toxic effects generally increase with increasing internal dose of a xenobiotic chemicals [22] and organisms are exposed to the maximum external concentration of a single chemical at its maximal toxic effects at its water solubility level, oxidative stress indicators were also tested at concentrations close to the water solubility level of the three chemicals. As described above, PDMS sheets were loaded with each chemical at the maximum water soluble concentration and at half the water solubility level, as shown in Table 1. To avoid organismal-level effects such as mortality, worms were exposed to each chemical for only 3 hours without food. 
Measurement of intracellular Reactive Oxygen Species Formation

C. elegans sampled after exposure were washed twice with $500 \mu \mathrm{L}$ of S-buffer and then incubated in $50 \mu \mathrm{M}$ 2,7-dichlorofluoroscein diacetate (D6883, Sigma-Aldrich) solution for 30 minutes at $20^{\circ} \mathrm{C}$. Next, the worms were transferred to a 96-black-well plate to detect fluorescence intensity or a slide glass to take a fluorescence image. The level of fluorescence intensity was measured using a Hidex Sense multi-detection microplate reader (Hidex, Turku, Finland) with excitation at $485 \mathrm{~nm}$ and emission at $530 \mathrm{~nm}$. The formation of ROS was visualized using a Leica DM IL microscope with a Leica DCF $42^{\circ} \mathrm{C}$ camera (Leica, Heerbrugg, Switzerland). A 2-mm tetramisole hydrochloride solution (L9756, Sigma-Aldrich) was used to fix C. elegans to take pictures of the live worms.

\section{Superoxide Dismutase Assay}

The activity of SOD was measured using an Oxiselect ${ }^{\mathrm{TM}} \mathrm{Su}-$ peroxide Dismutase Activity Assay kit (cat. STA-340; Cell Biolabs, Inc., San Diego, CA, USA). Collected worms were homogenized in $400 \mu \mathrm{L}$ of cold $1 \times$ lysis buffer ( $10 \mathrm{mM}$ Tris, $\mathrm{pH} 7.5,150$ $\mathrm{mM} \mathrm{NaCl}$, and $0.1 \mathrm{mM}$ ethylenediaminetetraacetic acid). The crude homogenate was centrifuged for 10 minutes at 12000 $\operatorname{rpm}\left(4^{\circ} \mathrm{C}\right)$ and the tissue lysate supernatant was collected and stored at $-80^{\circ} \mathrm{C}$ until enzyme analysis. Superoxide $\left(\mathrm{O}_{2}^{-}\right)$were generated by the xanthine/xanthine oxidase system and then detected with chromogen solution by measuring the absorbance reading at $490 \mathrm{~nm}$ using a PowerWave ${ }^{\mathrm{TM}} \mathrm{XS}$ microplate spectrophotometer (Bio Tek, Winooski, VT, USA). SOD activity was determined as the inhibition of chromogen reduction.

\section{Total Glutathione Assay}

The level of GSH was determined using an Oxiselect ${ }^{\mathrm{TM}}$ Total Glutathione Assay kit (cat. STA-312; Cell Biolabs, San Diego, CA, USA). The whole sample containing $10 \mathrm{mg}$ of tissue (dry weight) was homogenized in $200 \mu \mathrm{L}$ of ice-cold $5 \%$ metaphosphoric acid and then centrifuged at $12000 \mathrm{rpm}$ and $4^{\circ} \mathrm{C}$ for 15 minutes. The collected supernatant was stored at $-80^{\circ} \mathrm{C}$. In the presence of NADPH, oxidized glutathione (GSSG) is transformed to reduced GSH by GSH reductase. The chromogen reacts with the thiol group to produce a colored compound that absorbs at $405 \mathrm{~nm}$ with a Multi-Detection Microplate Reader (Hidex Sense). The total GSH content in samples was determined by comparison with a predetermined GSH standard curve.

\section{Lipid Peroxidation Assay}

The Oxiselect ${ }^{\mathrm{TM}}$ TBARS Assay kit (cat. STA-330; Cell Biolabs) was used for the direct quantitative measurement of malondialdehyde (MDA). Tissue samples were homogenized with 300 $\mu \mathrm{L}$ of phosphate buffer saline containing $3 \mu \mathrm{L}$ of $100 \times$ butylated hydroxytoluene. Homogenized samples were centrifuged at $12000 \mathrm{rpm}$ and $4^{\circ} \mathrm{C}$ for 5 minutes. The tissue lysate supernatant was collected, reacted with thiobarbituric acid at $95^{\circ} \mathrm{C}$ for 60 minutes. After all sample tubes were cooled on ice, they were centrifuged at $3000 \mathrm{rpm}$ for 15 minutes. Absorbance of the solution was read at $532 \mathrm{~nm}$ with a PowerWave ${ }^{\mathrm{TM}} \mathrm{XS}$ microplate spectrophotometer (Bio Tek). MDA content in a sample was determined by comparison with the predetermined MDA standard curve.

\section{Gene Expressions}

For quantitative gene expression analysis, C. elegans were homogenized in a glass Dounce tissue grinder (Wheaton, Millville, NJ, USA), and total mRNA was extracted using a NucleoSpin RNA kit (Macherey-Nagel GmbH \& Co., Düren, Germany) according to the manufacturer's instructions. Quantitative real-time polymerase chain reaction (PCR) amplification was performed using iQ SYBR Green Supermix (Bio-Rad, Hercules, CA, USA) on an Eco Real-Time PCR System (Illumina, San Diego, CA, USA). Primers were designed according to the sequences retrieved from the C. elegans database (www.wormbase.org). Twelve primers were classified under two classes as oxidative stress-related genes and CYP subfamily genes (Table S1). Gene expression was normalized to the level of the glyceraldehyde 3-phosphate dehydrogenase gene, gdp-1.

\section{Statistical Comparison of Oxidative Markers and Gene Expressions}

A parametric $t$-test was conducted to compare worms exposed to each test chemical and the control at $95 \%$ and $99 \%$ confidence level for gene expression tests. A single factor analysis of variance and Duncan's multiple range test were conducted to compare the control and all exposed groups at $95 \%$ confidence level for all oxidative stress markers.

\section{RESULTS}

Oxidative Stress-related Responses at the Same Aqueous Concentration

When worms were exposed to the same external concentrations, 4.0 and $8.0 \mu \mathrm{g} / \mathrm{L}$ of test chemicals, the formation of ROS was much higher in worms exposed to 9,10-DMA than for worms exposed to Ant and 9-MA (Figure 1A). After 6 hours of exposure, 9,10 -DMA ( $8 \mu \mathrm{g} / \mathrm{L}$ ) led to up to a $41 \%$ increase in ROS formation over that of the control. After 12 hours of expo- 

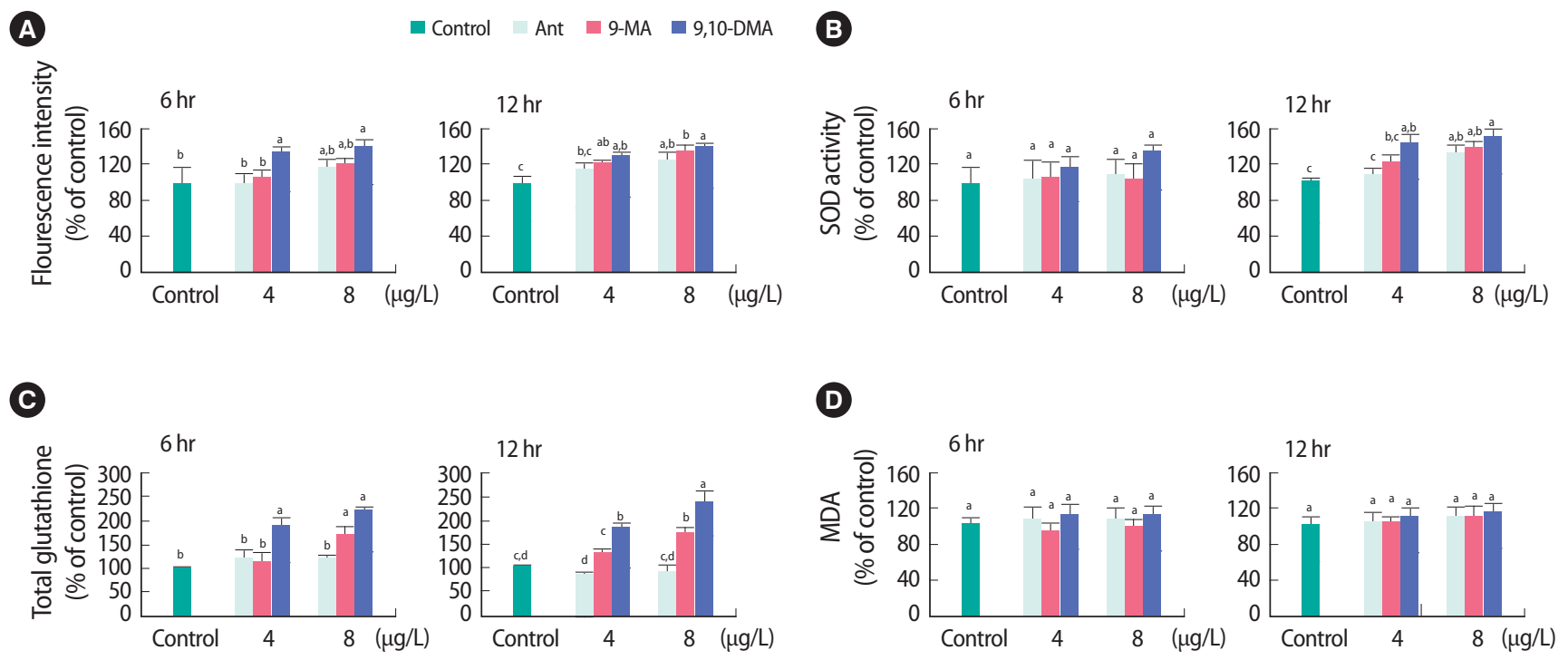

Figure 1. Oxidative stress markers investigated in C. elegans exposed to same concentrations (4 and $8 \mu \mathrm{g} / \mathrm{L}$ ) of Ant, 9-MA, and 9,10-DMA for 6 hours and 12 hours. (A) The formation of reactive oxygen species detected using the fluorescence intensity by 2,7-dichlorofluoroscein diacetate staining, (B) the percentage of superoxide dismutase (SOD) activity, (C) total glutathione, and (D) lipid peroxidation measured as malondialdehyde (MDA) concentration. Error bars denote standard deviations. The letters represent statistical significance $(p<0.05)$ determined by Duncan's multiple range test. Ant, anthracene: 9-MA, 9-methylanthracene; 9,10-DMA, 9,10-dimethylanthracene.

sure, the increase in ROS formation compared with that of the control reached 25, 34, and 40\% for Ant, 9-MA, and 9,10-DMA, respectively. The activity of SOD exhibited a similar trend as that of ROS formation. When worms were exposed to $8 \mu \mathrm{g} / \mathrm{L}, 6$ hours exposure to 9,10-DMA led a 35\% increase in SOD activity relative to that of the control (Figure 1B). After 12 hours exposure, SOD activity in worms exposed to the maximum concentration of all three chemicals increased significantly $(p<0.05)$ by more than $30 \%$. Notably, $8 \mu \mathrm{g} / \mathrm{L} 9,10$-DMA produced the highest SOD activity (49\% higher than that of the control) after 12 hours exposure. The level of total GSH in 9,10-DMA-exposed groups was significantly higher than those in other groups, regardless of exposure duration (Figure 1C). After 6 and 12 hours exposure to $8 \mu \mathrm{g} / \mathrm{L}$ 9,10-DMA, total GSH increased by 75 and 138\%, respectively. No significant differences in the lipid peroxidation assay were observed among different groups (Figure 1D).

Table 2 presents the expression of oxidative stress-related genes (daf-2, sir-2.1, daf-16, sod-1, sod-2, and sod-3). In the case of exposure to Ant and 9-MA, observed gene expression was slightly greater than that of the control. However, the expression of all genes in worms exposed to 9,10-DMA was more than double that of the control at $8 \mu \mathrm{g} / \mathrm{L}$ after 6 hours exposure. Among the SOD genes, sod-1 gene expression increased up to 3.3-fold compared to that of the control.
Table 2. Relative expression of six oxidative stress-related genes measured by real-time PCR after 6 hours exposure of $C$. elegans to the same concentration of Ant, 9-MA, and 9,10-DMA

\begin{tabular}{lccc}
\hline \multirow{2}{*}{ Genes } & \multicolumn{3}{c}{ Test chemicals $(8 \mu \mathrm{g} / \mathrm{L})$} \\
\cline { 2 - 4 } & \multicolumn{1}{c}{ Ant } & 9-MA & $9,10-\mathrm{DMA}$ \\
\hline daf-2 & $1.39 \pm 0.31$ & $1.49 \pm 0.47$ & $2.13 \pm 0.30^{\star *}$ \\
sir-2.1 & $1.66 \pm 0.21^{* *}$ & $1.77 \pm 0.27^{\star *}$ & $2.20 \pm 0.33^{\star *}$ \\
daf-16 & $2.13 \pm 0.44^{\star}$ & $1.93 \pm 0.46$ & $2.76 \pm 0.47^{\star *}$ \\
sod-1 & $2.00 \pm 0.42^{\star}$ & $2.23 \pm 0.38^{\star *}$ & $3.28 \pm 0.49^{\star *}$ \\
sod-2 & $1.60 \pm 0.20$ & $1.52 \pm 0.29$ & $2.31 \pm 0.35^{\star}$ \\
sod-3 & $1.42 \pm 0.26$ & $1.38 \pm 0.02^{*}$ & $1.93 \pm 0.29^{\star *}$ \\
\hline
\end{tabular}

Values are presented as mean \pm standard deviation.

All results were normalized to the gpd-1 and were presented in arbitrary units relative to control.

PCR, polymerase chain reaction; Ant, anthracene; 9-MA, 9-methylanthracene; 9,10-DMA, 9,10-dimethylanthracene.

${ }^{*} p<0.05,{ }^{* *} p<0.01$; replicated $\mathrm{n}=5$.

\section{Oxidative Stress-related Responses at Maximum Water}

\section{Soluble Concentrations}

Figure 2 describes oxidative stress-related responses obtained from TEST II using exposure concentrations at the water solubility limit of the test chemicals. The ROS levels in the presence of 9,10-DMA increased by approximately $30-37 \%$ compared with that of the control; however, the fluorescence signals caused by Ant and 9-MA exposure were not statistically different from the control (Figure 2A). In the SOD activity test, exposure to 9-MA produced a level of enzyme activity similar to that produced by 9,10 -DMA, although the exposure concentration was 50 times higher than that of 9,10-DMA (Figure 

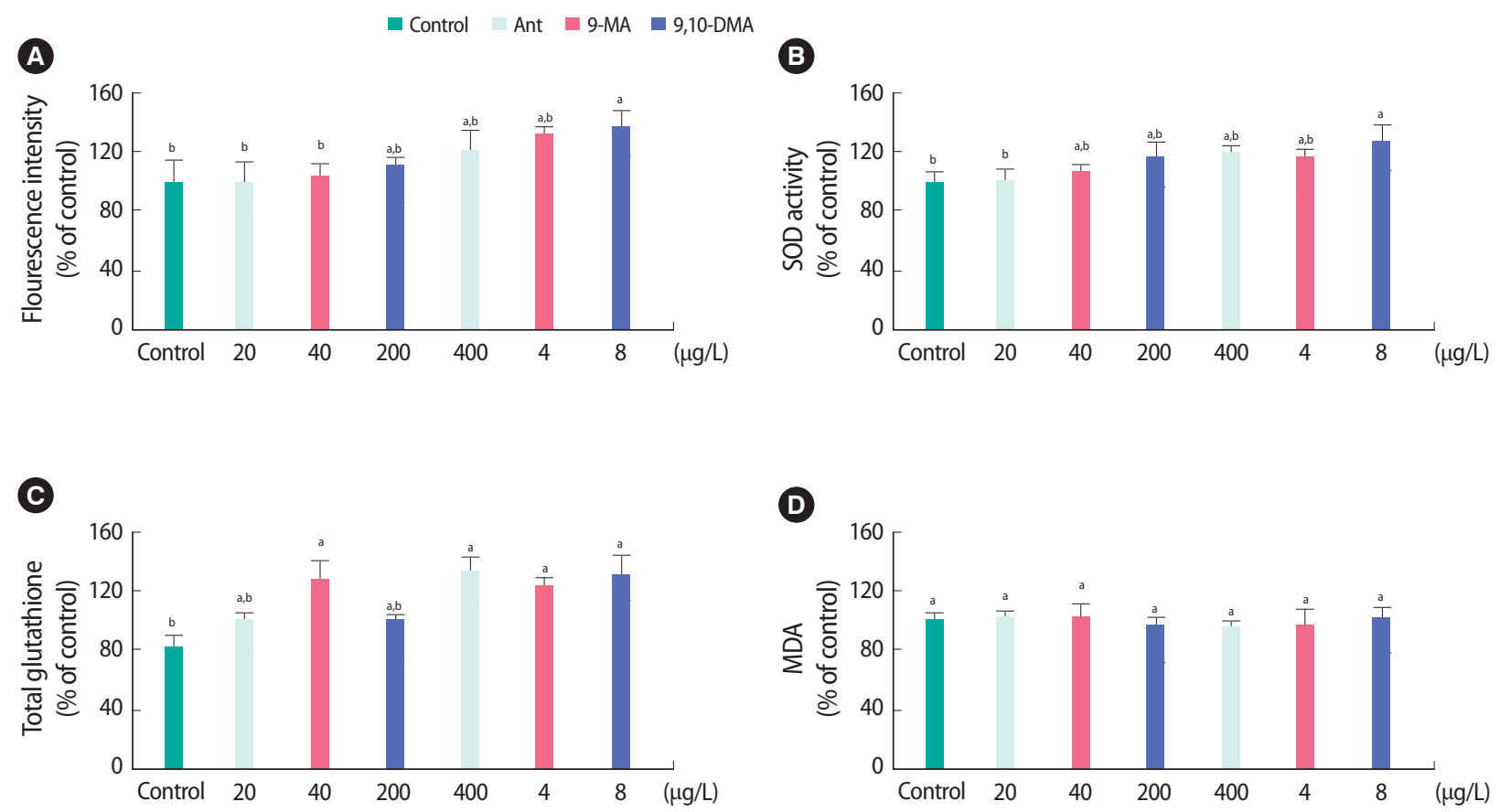

Figure 2. Oxidative stress markers investigated in C. elegans exposed to the concentration close to the water solubility of Ant, 9-MA, and 9,10-DMA for 3 hours. (A) The formation of reactive oxygen species (ROS) detected using the fluorescence intensity by 2,7-dichlorofluoroscein diacetate staining, (B) the percentage of superoxide dismutase (SOD) activity, (C) total glutathione, and (D) lipid peroxidation measured as malondialdehyde (MDA) concentration. Error bars denote standard deviations. The letters represent statistical significance $(p<0.05)$ determined by Duncan's multiple range test. Ant, anthracene; 9 -MA, 9-methylanthracene; 9,10-DMA, 9,10-dimethylanthracene.

Table 3. Relative expression of six oxidative stress-related genes measured by a real-time PCR after 3 hours exposure of $C$. elegans to the maximum water soluble concentrations of Ant, 9-MA, and 9,10-DMA

\begin{tabular}{lccc}
\hline \multirow{3}{*}{ Genes } & \multicolumn{3}{c}{ Test chemicals } \\
\cline { 2 - 4 } & Ant $(40 \mu \mathrm{g} / \mathrm{L})$ & 9-MA $(400 \mu \mathrm{g} / \mathrm{L})$ & $9,10-\mathrm{DMA}(8 \mu \mathrm{g} / \mathrm{L})$ \\
\hline daf-2 & $2.81 \pm 0.51^{*}$ & $3.20 \pm 0.61^{* *}$ & $2.62 \pm 0.32^{* *}$ \\
sir-2.1 & $2.02 \pm 0.33^{*}$ & $2.14 \pm 0.20^{\star *}$ & $2.00 \pm 0.11^{*}$ \\
daf-16 & $2.60 \pm 0.43^{\star *}$ & $4.22 \pm 0.27^{\star *}$ & $2.17 \pm 0.33^{\star *}$ \\
sod-1 & $1.94 \pm 0.48^{*}$ & $2.19 \pm 0.02^{\star *}$ & $2.13 \pm 0.25^{\star *}$ \\
sod-2 & $1.47 \pm 0.27$ & $1.43 \pm 0.26$ & $1.50 \pm 0.31$ \\
sod-3 & $1.40 \pm 0.34^{* *}$ & $1.46 \pm 0.26$ & $1.59 \pm 0.08^{* *}$ \\
\hline
\end{tabular}

Values are presented as mean \pm standard deviation.

All results were normalized to the gpd-1 and were presented in arbitrary units relative to control.

PCR, polymerase chain reaction; Ant, anthracene; 9-MA, 9-methylanthracene; 9,10DMA, 9,10-dimethylanthracene.

${ }^{*} p<0.05,{ }^{* *} p<0.01$; replicated $n=5$.

2B). When worms were exposed to maximum concentrations for 3 hours, total GSH increased approximately $60 \%$ relative to that of the control, regardless of the chemical. Total GSH measured in the $1 / 2$ water soluble concentration of 9,10-DMA ( 4.0 $\mu \mathrm{g} / \mathrm{L}$ ) increased by $52 \%$ relative to that of the control (Figure 2C). In the MDA assay (Figure 2D), lipid peroxidation did not show any significant response under any exposure concentration in TEST I.
As shown in Table 3, the expression of genes showed a similar trend (1.5-2-fold increases) for Ant, 9-MA, and 9,10-DMA, with the exception of abnormal dauer formation gene-16 (daf16). The expression of the daf-16 genes reached a peak level when worms were exposed to $400 \mu \mathrm{g} / \mathrm{L}$ of 9-MA. After 3-hour exposure to the highest concentrations (Ant: $40 \mu \mathrm{g} / \mathrm{L}$, 9-MA: $400 \mu \mathrm{g} / \mathrm{L}, 9,10-\mathrm{DMA}: 8 \mu \mathrm{g} / \mathrm{L}$ ), daf-16 expression was 2.60, 4.22, and 2.17 times that of the control, respectively.

\section{Toxic Response of Xenobiotic Metabolism-related Cytochrome P450 Genes}

In TEST I, only cyp35a1, among all metabolism-related genes, was significantly expressed approximately 2 -fold more than in the control, regardless of the chemical (Figure 3A). When gene expression was examined at the chemical's water solubility level, expression of all genes was increased in the order: 9,10-DMA > Ant > 9-MA (Figure 3B). In particular, expression of the cyp35al gene was up to 6.5-fold higher than that of the control after 3 hours exposure to $400 \mu \mathrm{g} / \mathrm{L}$ 9-MA. When worms were exposed to $40 \mu \mathrm{g} / \mathrm{L}$ Ant for 3 hours, expression of the cyp35al gene was 4 times that of the control. 

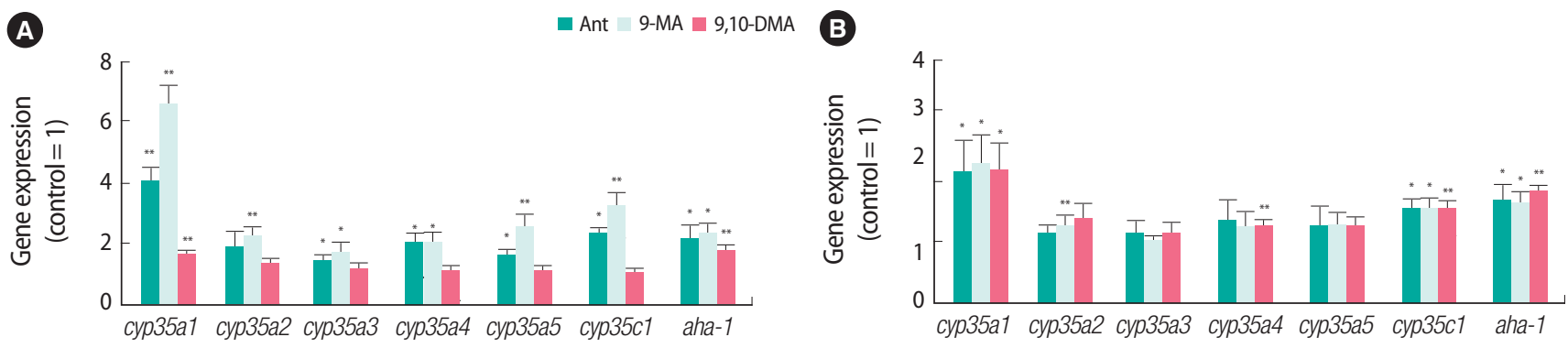

Figure 3. Relative expression of cytochrome P450 35 family genes in $C$. elegans measured by a real-time PCR after 3 hours exposed at the water solubility limit (Ant, $40 \mu \mathrm{g} / \mathrm{L} ; 9-\mathrm{MA}, 400 \mu \mathrm{g} / \mathrm{L}$; and 9,10-DMA, $8 \mu \mathrm{g} / \mathrm{L}$ ) (A) and 6 hours exposure to the same external concentration (8 $\mu \mathrm{g} / \mathrm{L})$ (B). Gene expression was normalized to the $g p d-1$. Data are presented in arbitrary units relative to control. Error bars denote standard deviations. PCR, polymerase chain reaction; Ant, anthracene; 9-MA, 9-methylanthracene; 9,10-DMA, 9,10-dimethylanthracene. ${ }^{*} p<0.05,{ }^{* \star} p<0.01$; replicated $n=5$.

\section{DISCUSSION}

\section{Comparison of Toxic Potential at the Same External Aqueous Concentration}

Because the free concentrations of the three chemicals in the test medium were maintained at the same level by the passive dosing method, results from TEST I can be used to compare their toxic potentials at the same external dose. It is well known that the external dose is not directly related to toxic responses at target sites that is determined by the internal dose. Since the whole-body concentration is often assumed to be a good surrogate for internal concentration [23], the differences in oxidative stress markers in C. elegans might be explained by the difference in the whole-body concentration resulting from different toxicokinetics. Reported values of the logarithm of the lipid-water partition coefficients ( $\mathrm{K}_{\text {lipw }}$ ) for Ant, 9-MA, and 9,10-DMA are 5.28 [24], 5.52, and 5.78 [25], respectively, as shown in Table 1. According to a simple one-box bioconcentration model, the uptake rate constant is not likely to differ among test compounds, but the elimination rate constant decreases with increasing $\mathrm{K}_{\text {lipw }}$ [26]. Thus, the whole body concentration of Ant, 9-MA, and 9,10-DMA could be in the order of 9,10-DMA > 9-MA > Ant at the same external concentration if other processes, such as metabolic transformation, do not differ considerably. The observed increase in oxidative stress end-points with increasing alkylation using the same external exposure concentration might be explained by the increase in $K_{\text {lipw }}$, which results in higher internal concentration at the same external concentration. This hypothesis was further tested with TEST II, as discussed below.

\section{Comparison of Toxic Potential Within the Limit of Aqueous Solubility}

Figure 2A shows that the ROS level induced by exposure to 9,10-DMA was the highest, even if 9,10-DMA had the lowest external concentration. Because $K_{\text {lipw }}$ values for the three chemicals are within one order of magnitude, the internal concentration of 9,10-DMA would be the lowest unless there are notable differences in the metabolic transformation rates among them. In general, the expression of oxidative-stress indicators increased with increasing degree of alkylation, implying that alkylation increases the ease of electron donation to initiate a series reactions involved in the reduction of oxygen.

Most ROS are formed in the intermediate steps of the reduction of molecular oxygen $\left(\mathrm{O}_{2}\right)$. The $\mathrm{O}_{2}$ in the body requires four electrons for complete reduction to water, and a one-electron step results in the formation of the $\mathrm{O}_{2}^{-}$. The $\mathrm{O}_{2}$ plays an important role in the formation of other ROS, such as hydrogen peroxide, the hydroxyl radical, and singlet oxygen, in living systems that use electrons provided by an electron donor [27]. Alkyl groups enrich the electron density of the $\pi$ electron system of aromatic hydrocarbons and facilitate electron excitation [28]. Although the mechanisms related to the $\pi$ electron transfer to oxygen to form superoxide ions are not fully understood, enriched electron density is a plausible explanation for accelerated ROS formation.

Results of antioxidant enzyme activity assays support the observation that oxidative stress is increased by the formation of ROS in worms exposed to alkyl-PAHs (Figures 1B and 1C, 2B and $2 \mathrm{C}$ ). SOD activity and the concentration of total GSH were increased in the order 9,10-DMA > 9-MA > Ant for all exposure concentrations. SOD catalyzes the reduction of $\mathrm{O}_{2}{ }^{-}$to hydrogen peroxide $\left(\mathrm{H}_{2} \mathrm{O}_{2}\right)$ and molecular $\mathrm{O}_{2} . \mathrm{H}_{2} \mathrm{O}_{2}$, in conjunction with the $\mathrm{O}_{2}$, is removed by GSH peroxidase, oxidizing the reduced GSH to form disulfide glutathione (GSSG) [29]. The increase in SOD activity and the total GSH concentration showed that methyl groups in alkylated PAH favored ROS formation and were involved in increasing oxidative stress. 
Changes in mRNA Expression Induced by Anthracene and Allyl-anthracene

The daf-2 gene, which encodes the insulin-like growth factor (IGF-1) involved in longevity and stress resistance and the sir-2.1 gene, the mammalian ortholog of which is SIRT1, are also known to modulate longevity and oxidative stress responses through regulating a downstream FOXO transcription factor, daf-16. These pathways resist oxidative stress and regulate the expression of ROS detoxification genes, such as sod-1, sod-2, and sod-3 [30-33]. In TEST I, the level of gene expression induced by 9,10DMA was slightly higher than that induced by the other compounds, whereas no significant differences were observed between Ant and 9-MA (Tables 2 and 3). The expression of mRNA partly supports that alkyl substitution of anthracene would increase ROS formation as presented in Figures $1 \mathrm{~A}$ and 2A.

It is well known that PAHs have strong binding affinity for the AHR, and are inducers of CYP. When worms were exposed to each maximal water-soluble concentration of the test chemicals, the expression of all cyp genes increased in the order 9-MA > Ant $>$ 9,10-DMA (Figure 3), whereas cyp gene expressions remained at a similar level in the same exposure concentration test, showing that cyp gene expression is proportional to the external concentration. This implies that residual concentrations of chemicals in the body could be an important factor that determines gene expression induced by binding of a $\mathrm{PAH}$ and a receptor. In particular, differences in expression of the cyp35al gene induced by target chemicals was enhanced depending on exposure concentrations that were strongly induced by PAHs and PCBs, as reported by Menzel et al. $[19,20]$. In addition, expression of the $d a f-$ 16 gene was highest when exposed to 9-MA at the water solubility. The transcription factor daf-16 promotes longevity in response to many input signals, including AMP kinase, JNK-1, SIR-2, AKT, and a kinase in the insulin/IGF-1 (daf-2) pathway, in addition to ROS [34]. 9-MA at a high external concentration $(400 \mu \mathrm{g} / \mathrm{L})$ may affect multiple sites in an organism, and thus many stress-related signals are continuously transferred into biological cascades, leading to the increased expression of daf-16, a comprehensive stress-related transcription factor.

\section{Comparison of Toxicity of anthracene and Alkyl-}

\section{anthracene With Literature Values}

The observed effect levels in this study were in general lower than those reported in earlier studies for Ant and 9-MA. To our best knowledge, there have been no reports on the ecotoxicity of 9,10-DMA. Sese et al. [21] investigated the toxicity of Ant on $C$. elegans by measuring growth at a 48-hour median effective concentration $\left(\mathrm{EC}_{50}\right)$ of $800 \mu \mathrm{g} / \mathrm{L}$, in which Ant was carried by acetone as a cosolvent and the reported $\mathrm{EC}_{50}$ value exceeded its wa- ter solubility. Several studies have reported that 2-day $\mathrm{EC}_{50}$ values for Ant in Daphnia were 36-750 $\mu \mathrm{g} / \mathrm{L}$ [9,35,36], and those of 9-MA were 130-440 $\mu \mathrm{g} / \mathrm{L}$ [9]. The range of exposure concentration in this study was 8-40 $\mu \mathrm{g} / \mathrm{L}$ for Ant and 8-400 $\mu \mathrm{g} / \mathrm{L}$ for 9-MA. Although they were similar to or lower than those used in other studies, the initial responses of oxidative stress at the molecular level were well identified. Furthermore, the passive dosing method provided constant exposure by overcoming the deficiencies of the conventional dosing method by spiking solvent carriers, such as the loss of hydrophobic compounds through binding with plastic surfaces [17]. In TEST II, C. elegans was exposed to a maximum water-soluble concentration for only for 3 hours, because behavioral abnormalities were observed after 6 hours when C. elegans was exposed to $400 \mu \mathrm{g} / \mathrm{L}$ 9-MA. This partly supports that toxic effects of alkyl-Ant could be seen at lower levels than observed in earlier studies via oxidative stress.

\section{ACKNOWLEDGEMENTS}

The authors thank Dr. Jinhee Choi (School of Environmental Engineering, University of Seoul) for the use of a fluorescence microscope and Ms. Da-Eun Byun for her laboratory assistance. This research was partly supported by the National Research Foundation of Korea (NRF) (grant no. 2013R1A1A2060473), research project entitled 'Oil Spill Environmental Impact Assessment and Environmental Restoration (PM57431)' funded by the Ministry of Oceans and Fisheries of Korea, Korea Ministry of Environment (MOE) as "The Chemical Accident Prevention Technology Development Project", and a Korea University Grant.

\section{CONFLICT OF INTEREST}

The authors have no conflicts of interest associated with the material presented in this paper.

\section{SUPPLEMENTARY MATERIALS}

Supplementary Material 1: Table S1 is available at https:// www.e-eht.org/.

\section{ORCID}

Jung-Hwan Kwon http://orcid.org/0000-0002-6341-7562

\section{REFERENCES}

1. Han J, Won EJ, Hwang DS, Shin KH, Lee YS, Leung KM, et al. Crude oil exposure results in oxidative stress-mediated dysfunctional develop- 
ment and reproduction in the copepod Tigriopus japonicus and modulates expression of cytochrome P450 (CYP) genes. Aquat Toxicol 2014;152:308-317.

2. Zhao Y, Hong B, Fan Y, Wen M, Han X. Accurate analysis of polycyclic aromatic hydrocarbons (PAHs) and alkylated PAHs homologs in crude oil for improving the gas chromatography/mass spectrometry performance. Ecotoxicol Environ Saf 2014;100:242-250.

3. Agency for Toxic Substances and Disease Registry. Toxicological profile for polycyclic aromatic hydrocarbons (PAHs) [cited 2018 Mar 3]. Available from: https://www.atsdr.cdc.gov/toxprofiles/tp.asp?id=122\&tid=25.

4. Yan J, Wang L, Fu PP, Yu H. Photomutagenicity of 16 polycyclic aromatic hydrocarbons from the US EPA priority pollutant list. Mutat Res 2004;557(1):99-108.

5. Yim UH, Ha SY, An JG, Won JH, Han GM, Hong SH, et al. Fingerprint and weathering characteristics of stranded oils after the Hebei Spirit oil spill. J Hazard Mater 2011;197:60-69.

6. Kang HJ, Lee SY, Roh JY, Yim UH, Shim WJ, Kwon JH. Prediction of ecotoxicity of heavy crude oil: contribution of measured components. Environ Sci Technol 2014;48(5):2962-2970.

7. Lee CH, Lee JH, Sung CG, Moon SD, Kang SK, Lee JH, et al. Monitoring toxicity of polycyclic aromatic hydrocarbons in intertidal sediments for five years after the Hebei Spirit oil spill in Taean, Republic of Korea. Mar Pollut Bull 2013;76(1-2):241-249.

8. Liu Z, Liu J, Zhu Q, Wu W. The weathering of oil after the Deepwater Horizon oil spill: insights from the chemical composition of the oil from the sea surface, salt marshes and sediments. Environ Res Lett 2012;7(3):035302.

9. Bobra AM, Shiu WY, Mackay D. A predictive correlation for the acute toxicity of hydrocarbons and chlorinated hydrocarbons to the water flea (Daphniamagna). Chemosphere 1983;12(9-10):1121-1129.

10. Fallahtafti S, Rantanen T, Brown RS, Snieckus V, Hodson PV. Toxicity of hydroxylated alkyl-phenanthrenes to the early life stages of Japanese medaka (Oryzias latipes). Aquat Toxicol 2012;106-107:56-64.

11. Gardiner WW, Word JQ, Word JD, Perkins RA, McFarlin KM, Hester BW, et al. The acute toxicity of chemically and physically dispersed crude oil to key Arctic species under Arctic conditions during the open water season. Environ Toxicol Chem 2013;32(10):2284-2300.

12. Lin H, Morandi GD, Brown RS, Snieckus V, Rantanen T, Jørgensen KB, et al. Quantitative structure-activity relationships for chronic toxicity of alkyl-chrysenes and alkyl-benz[a]anthracenes to Japanese medaka embryos (Oryzias latipes). Aquat Toxicol 2015;159:109-118.

13. Rhodes S, Farwell A, Hewitt LM, MacKinnon M, Dixon DG. The effects of dimethylated and alkylated polycyclic aromatic hydrocarbons on the embryonic development of the Japanese medaka. Ecotoxicol Environ Saf 2005;60(3):247-258.

14. Mu J, Wang J, Jin F, Wang X, Hong H. Comparative embryotoxicity of phenanthrene and alkyl-phenanthrene to marine medaka (Oryzias melastigma). Mar Pollut Bull 2014;85(2):505-515.

15. Salaberria I, Brakstad OG, Olsen AJ, Nordtug T, Hansen BH. Endocrine and AhR-CYP1A pathway responses to the water-soluble fraction of oil in zebrafish (Danio rerio Hamilton). J Toxicol Environ Health A 2014;77(9-11):506-515.

16. Schlezinger JJ, Liu D, Farago M, Seldin DC, Belguise K, Sonenshein GE, et al. A role for the aryl hydrocarbon receptor in mammary gland tumorigenesis. Biol Chem 2006;387(9):1175-1187.

17. Roh JY, Lee H, Kwon JH. Changes in the expression of cyp35a family genes in the soil nematode Caenorhabditis elegans under controlled exposure to chlorpyrifos using passive dosing. Environ Sci Technol 2014;48(17):10475-10481.

18. Roh JY, Lee HJ, Kwon JH. Internal concentration and time are important modifiers of toxicity: the case of chlorpyrifos on Caenorhabditis elegans. Environ Sci Technol 2016;50(17):9689-9696.

19. Menzel R, Bogaert T, Achazi R. A systematic gene expression screen of Caenorhabditis elegans cytochrome P450 genes reveals CYP35 as strongly xenobiotic inducible. Arch Biochem Biophys 2001;395(2): 158-168.

20. Menzel R, Rödel M, Kulas J, Steinberg CE. CYP35: xenobiotically induced gene expression in the nematode Caenorhabditis elegans. Arch Biochem Biophys 2005;438(1):93-102.

21. Sese BT, Grant A, Reid BJ. Toxicity of polycyclic aromatic hydrocarbons to the nematode Caenorhabditis elegans. J Toxicol Environ Health A 2009;72(19):1168-1180.

22. Zakrzewski SF. Environmental toxicology. 3rd ed. Oxford: Oxford University Press; 2002, p. 334.

23. Escher BI, Hermens JL. Internal exposure: linking bioavailability to effects. Environ Sci Technol 2004;38(23):455A-462A.

24. van der Heijden SA, Jonker MT. Evaluation of liposome-water partitioning for predicting bioaccumulation potential of hydrophobic organic chemicals. Environ Sci Technol 2009;43(23):8854-8859.

25. Kang HJ, Lee SY, Kwon JH. Physico-chemical properties and toxicity of alkylated polycyclic aromatic hydrocarbons. J Hazard Mater 2016;312:200-207.

26. Gobas FA, Opperhuizen A, Hutzinger O. Bioconcentration of hydrophobic chemicals in fish: relationship with membrane permeation. Environ Toxicol Chem 1986;5(7):637-646.

27. Hodgson E. A textbook of modern toxicology. 4th ed. Hoboken: Wiley; 2010, p. 267-268.

28. Stout SA, Wang Z. Standard handbook oil spill environmental forensics: fingerprinting and source identification. 2nd ed. London; Academic Press; 2016, p. 934.

29. Di Giulio RT, Washburn PC, Wenning RJ, Winston GW, Jewell CS. Biochemical responses in aquatic animals: a review of determinants of oxidative stress. Environ Toxicol Chem 1989;8(12):1103-1123.

30. Honda Y, Honda S. The daf-2 gene network for longevity regulates oxidative stress resistance and Mn-superoxide dismutase gene expression in Caenorhabditis elegans. FASEB J 1999;13(11):1385-1393.

31. Rizki G, Iwata TN, Li J, Riedel CG, Picard CL, Jan M, et al. The evolutionarily conserved longevity determinants HCF-1 and SIR-2.1/SIRT1 collaborate to regulate DAF-16/FOXO. PLoS Genet 2011;7(9): e1002235.

32. Gami MS, Wolkow CA. Studies of Caenorhabditis elegans DAF-2/insulin signaling reveal targets for pharmacological manipulation of lifespan. Aging Cell 2006;5(1):31-37.

33. Hesp K, Smant G, Kammenga JE. Caenorhabditis elegans DAF-16/ FOXO transcription factor and its mammalian homologs associate with age-related disease. Exp Gerontol 2015;72:1-7.

34. Kenyon CJ. The genetics of ageing. Nature 2010;464(7288):504-512.

35. Munoz MJ, Tarazona JV. Synergistic effect of two-and four-component combinations of the polycyclic aromatic hydrocarbons: phenanthrene, anthracene, naphthalene and acenaphthene on Daphnia magna. Bull Environ Contam Toxicol 1993;50(3):363-368.

36. Smith SB, Savino JF, Blouin MA. Acute toxicity to Daphnia pulex of six classes of chemical compounds potentially hazardous to Great Lakes aquatic biota. J Great Lakes Res 1988;14(4):394-404. 